\title{
Frogs and Toads of Northern Belize ${ }^{1}$
}

\author{
Jenna M. Cole, Sarah K. Cooke, Venetia S. Briggs-Gonzalez, Justin R. Dalaba, and Frank J. \\ Mazzotti $^{2}$
}

\section{Frogs, Toads, and Conservation}

There are 35 species of frogs and toads (38 amphibian species) recorded in Belize. Here we present some of the most common species found in and around Lamanai and the New River watershed.

Frogs and toads have played an important role in ancient Maya culture and can be seen in drawings and figurines. Most species emerge with summer rains to breed, and males are often found calling in a chorus in or near water. Females deposit eggs in or above water, and tadpoles develop into young frogs within a few weeks.

Because they are tied to water to complete their life cycle, amphibians are indicators of ecosystem health. They are susceptible to pesticides (including repellants and perfumes), disease, and environmental pollution because of their semi-permeable skin. There have been worldwide declines in amphibian populations as a result of habitat destruction, urbanization, and the increasing prevalence of chytrid fungus, which is lethal in some species and causes deformities in others. Belize is home to several threatened frog species and the endemic Maya mountains frog, Lithobates juliani. With increased threats, their future is at risk. This fact sheet will help you identify your frogs and toads in order to better protect them.

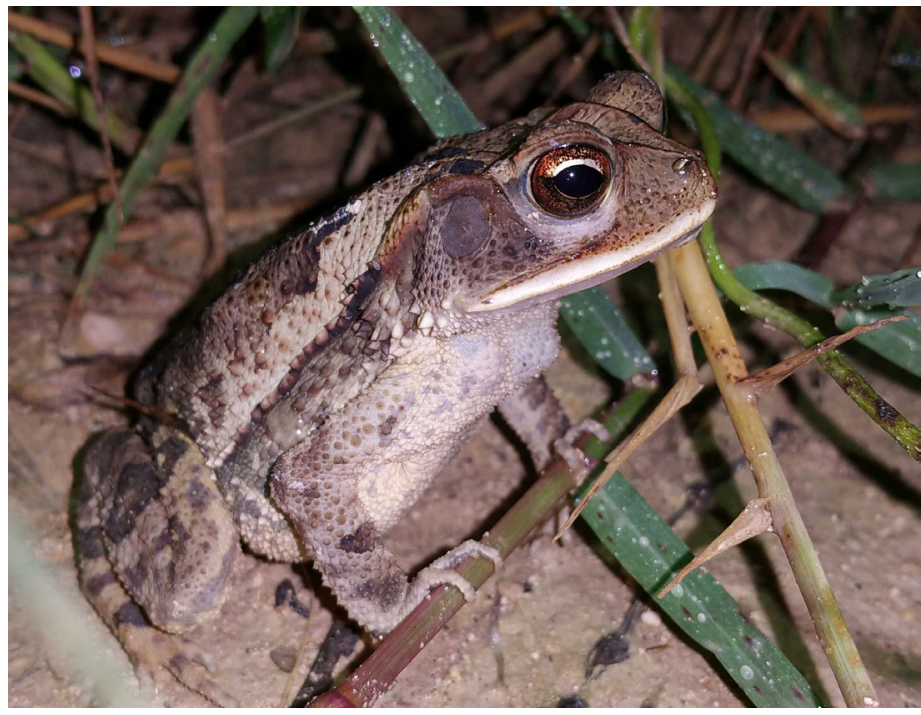

Figure 1. Gulf Coast toad (Incilius valliceps).

Credits: Michiko Squires, UF/IFAS

\section{Gulf Coast Toad}

Incilius valliceps, $73-100 \mathrm{~mm}$ (3.0-4.0 in)

This medium-sized terrestrial toad is common in disturbed habitats. Coloration varies from red or gray to deep brown with warts on the dorsal surface. They have short limbs with robust forearms and no webbing between the fingers.

1. This document is WEC394, one of a series of the Wildlife Ecology and Conservation Department, UF/IFAS Extension. Original publication date May 2018. Visit the EDIS website at http://edis.ifas.ufl.edu.

2. Jenna M. Cole, MS graduate student, Wildlife Ecology and Conservation Department; Sarah K. Cooke, MS graduate student, Wildlife Ecology and Conservation Department; Venetia S. Briggs-Gonzalez, research ecologist; Justin R. Dalaba, science writer and outreach coordinator; and Frank J. Mazzotti, professor, Wildlife Ecology and Conservation Department; UF/IFAS Fort Lauderdale Research and Education Center, Fort Lauderdale, FL 33314.

The Institute of Food and Agricultural Sciences (IFAS) is an Equal Opportunity Institution authorized to provide research, educational information and other services

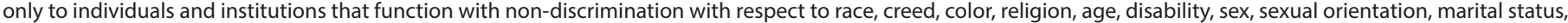

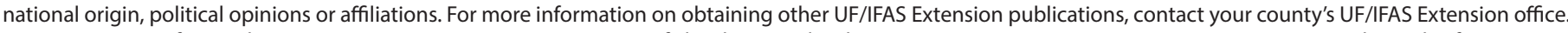
U.S. Department of Agriculture, UF/IFAS Extension Service, University of Florida, IFAS, Florida A \& M University Cooperative Extension Program, and Boards of County Commissioners Cooperating. Nick T. Place, dean for UF/IFAS Extension. 


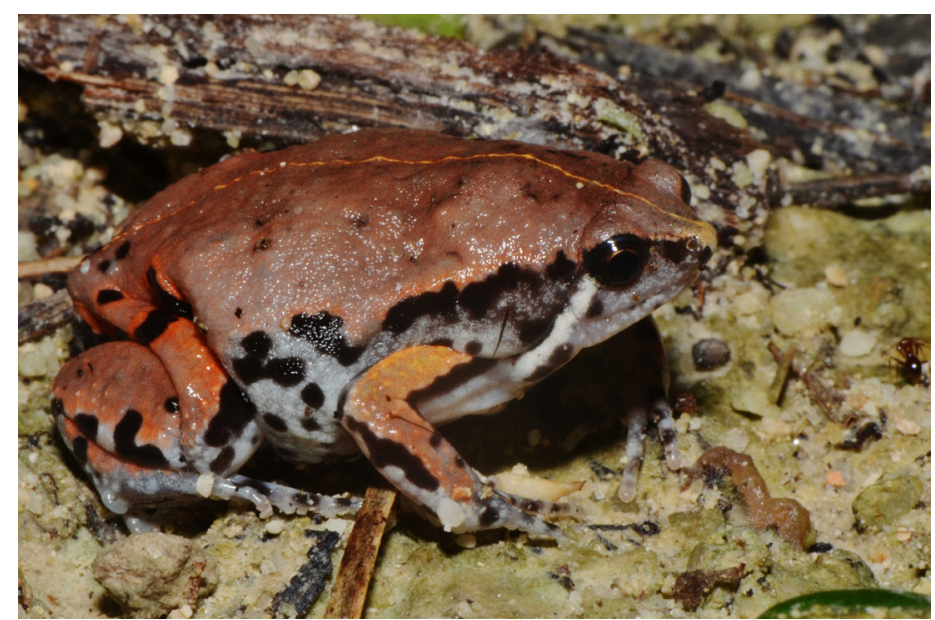

Figure 2. Sheep frog (Hypopachus variolosus).

Credits: Mike Rochford, UF/IFAS

\section{Sheep Frog}

Hypopachus variolosus, $30-45 \mathrm{~mm}$ (1.2-1.8 in)

A small terrestrial frog with a narrow face, small, stout body, and smooth, red-brown skin with a speckled underside. They have a thin white stripe from eye to base of forelimb. Vocalization is a nasal, sheep-like bleat. Active at night and feeds on ants and termites.

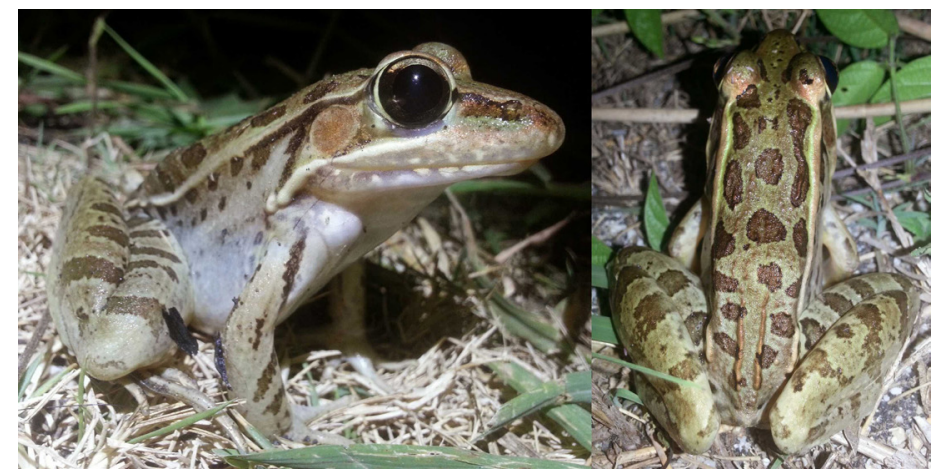

Figure 3. Rio Grande leopard frog (Rana berlandieri).

Credits: Michiko Squires, UF/IFAS

\section{Río Grande Leopard Frog}

Rana berlandieri, 65-114 mm (2.6-4.6 in)

Large, greenish-brown frog with dark spots and a pair of light-colored folds running down its back. It has long, muscular legs and leaps into water when startled. Common in freshwater habitats and active both day and night.

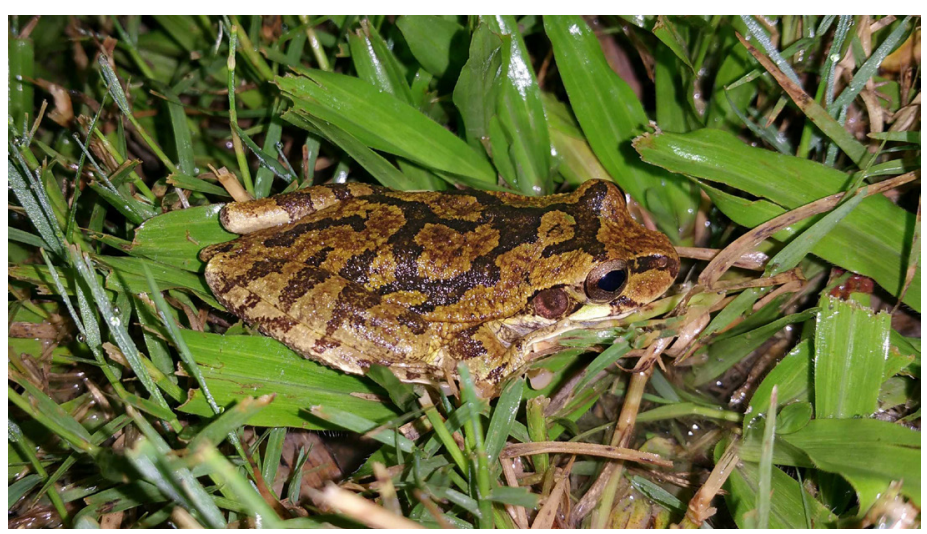

Figure 4. Mexican treefrog (Smilisca baudinii).

Credits: Michiko Squires, UF/IFAS

\section{Mexican Treefrog}

Smilisca baudinii, 50-77 mm (2.0-2.8 in)

Medium-sized, robust frog with large eyes. One of the most abundant frogs in Belize. Variable color and pattern, commonly referred to as "camouflage treefrog," usually olive, brown, or green with irregular dark blotches. Nocturnal, terrestrial, and arboreal, they are often seen clinging to the sides of buildings near lights and on roads after rains.

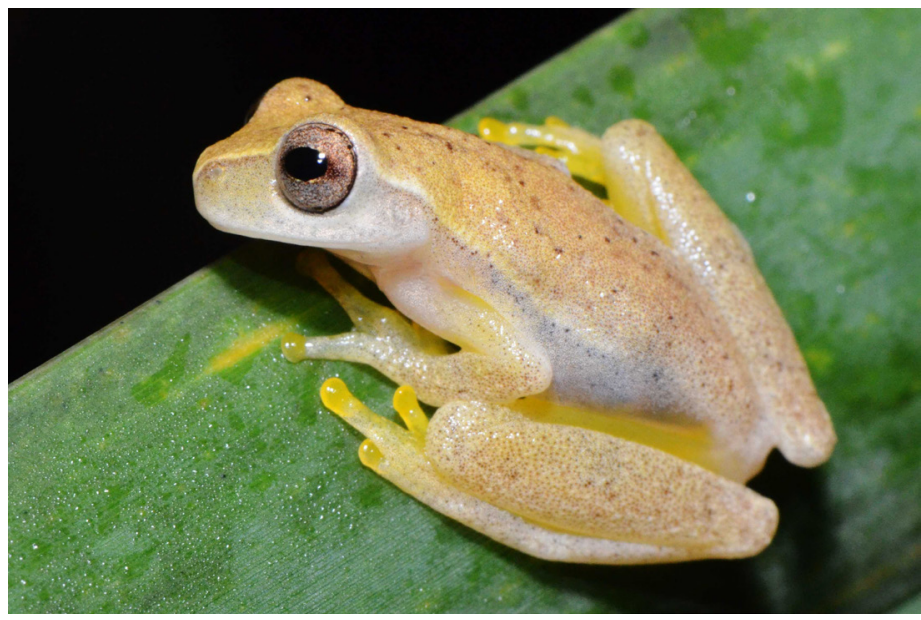

Figure 5. Yellow treefrog (Dendropsophus microcephalus). Credits: Mike Rochford, UF/IFAS

\section{Yellow Treefrog}

Dendropsophus microcephalus, $21-26 \mathrm{~mm}$ (0.6-1.0 in)

A small, nocturnal treefrog with large eyes and horizontally elliptical pupils. Coloration usually yellow-tan, gray, or orange with dark " $\mathrm{H}$ " or "X" pattern on back and bright yellow toes with toe pads. Common in disturbed areas but absent in forests. 


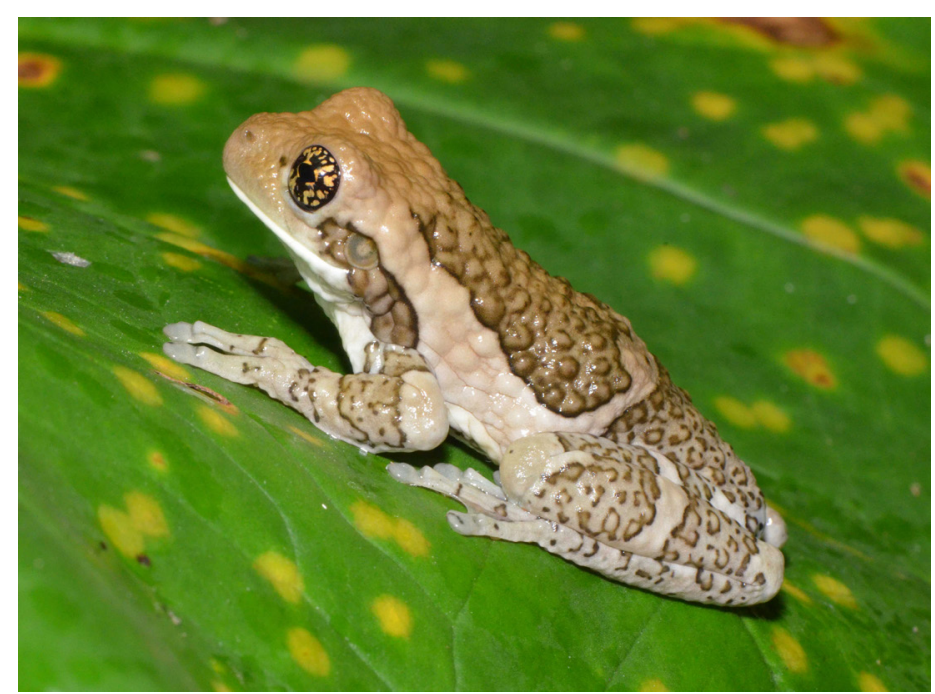

Figure 6. Veined treefrog (Trachycephalus venulosus).

Credits: Mike Rochford, UF/IFAS

\section{Veined Treefrog}

Trachycephalus venulosus, $70-102 \mathrm{~mm}$ (2.75-4.0 in)

Large-bodied treefrog that has rough, light-colored skin with darker blotches. Paired vocal sacs expand up and over the head during calling. Arboreal, terrestrial, and also found on building walls. Secretes a sticky, milky substance that is extremely irritating to eyes.

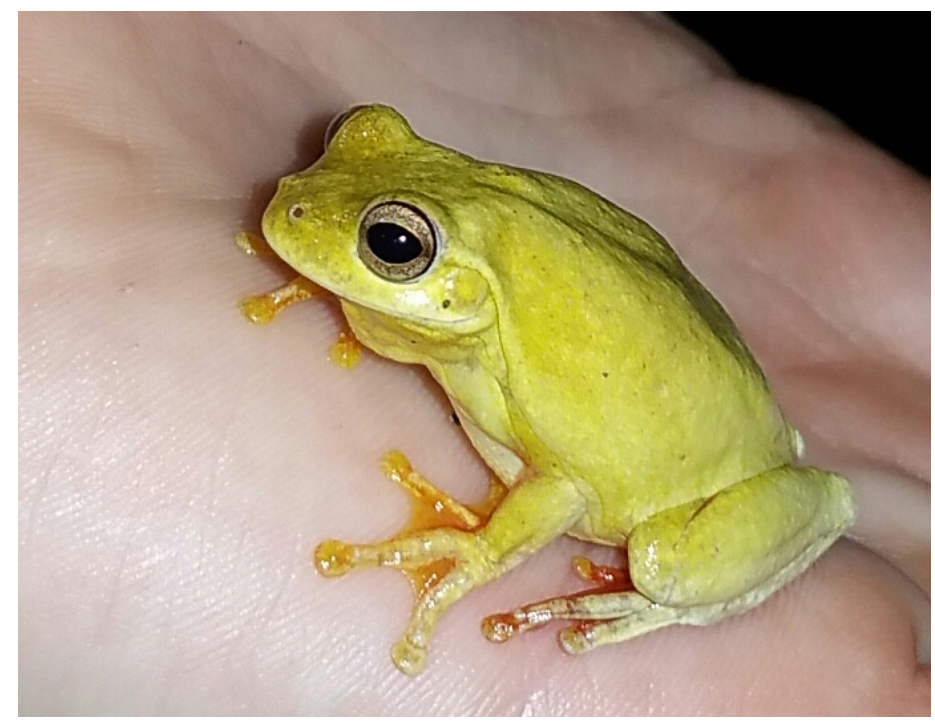

Figure 7. Mahogany treefrog (Tlalocohyla loquax).

Credits: Michiko Squires, UF/IFAS

\section{Mahogany Treefrog}

Tlalocohyla loquax, 33-38 mm (1.3-1.5 in)

A cream-colored, light brown or reddish frog with distinct reddish thighs and toe webbing. Primarily arboreal, but this nocturnal frog can also be found near freshwater ponds in both natural and disturbed areas.

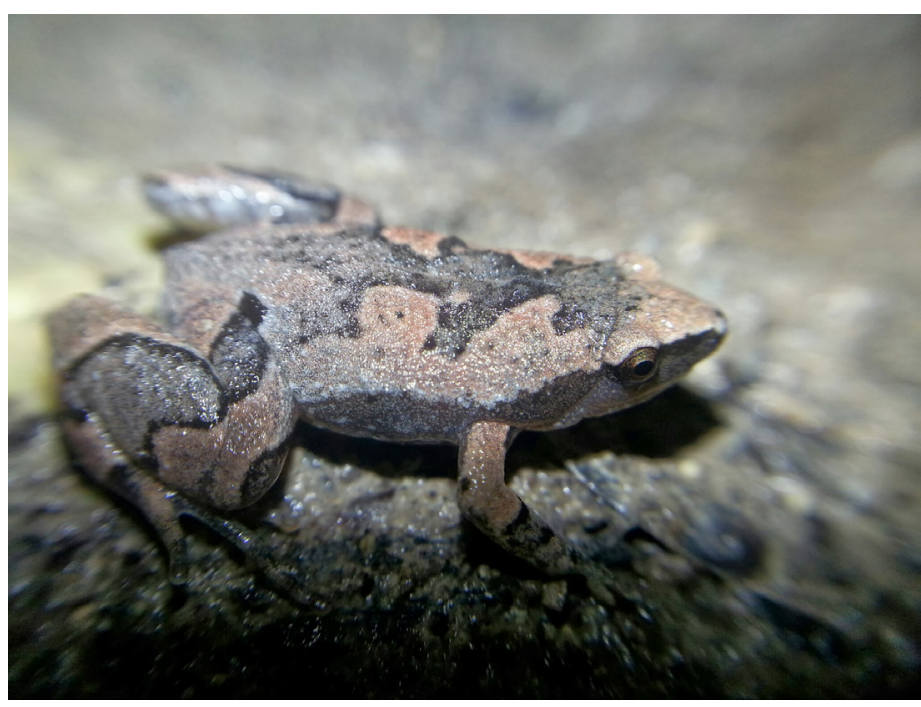

Figure 8. Elegant narrowmouth toad (Gastrophryne elegans). Credits: Michiko Squires, UF/IFAS

\section{Elegant Narrowmouth Toad}

Gastrophryne elegans, 22-38 mm (1.0-1.5 in)

A small, triangular toad with small eyes and stocky limbs. Gray or tan with dark blotches, usually outlined in black. Nocturnal and terrestrial, occurs in leaf litter but is not common.

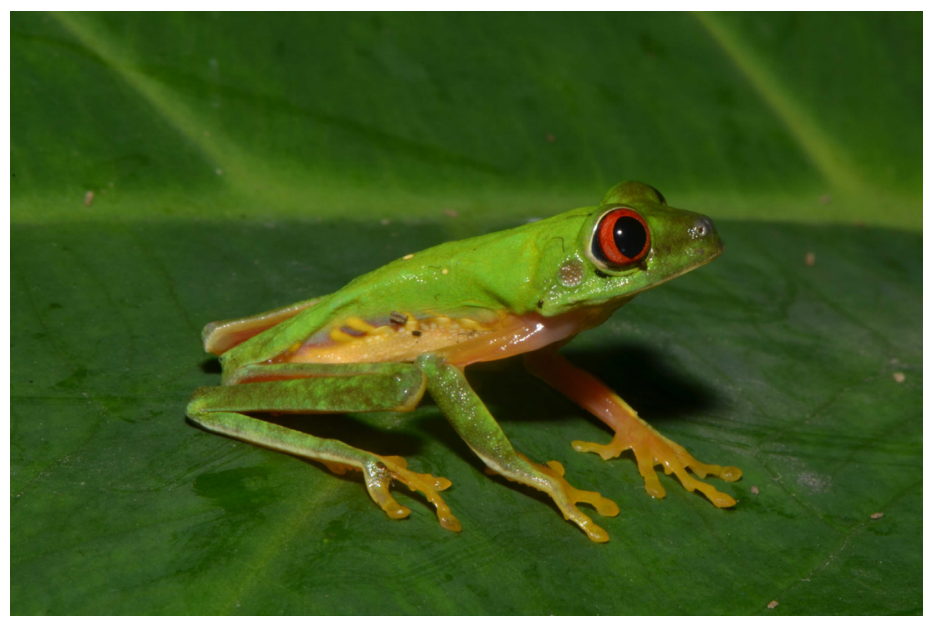

Figure 9. Red-eyed treefrog (Agalychnis callidryas).

Credits: Mike Rochford, UF/IFAS

\section{Red-Eyed Treefrog}

Agalychnis callidryas, 45-65 mm (1.8-2.6 in)

Large but slender bright green treefrog with red eyes that have conspicuous vertically elliptical pupils. Vocalization is a "chac" heard on rainy summer nights. Amplectant pairs are visible on the underside of leaves overhanging water, where females lay egg masses. 


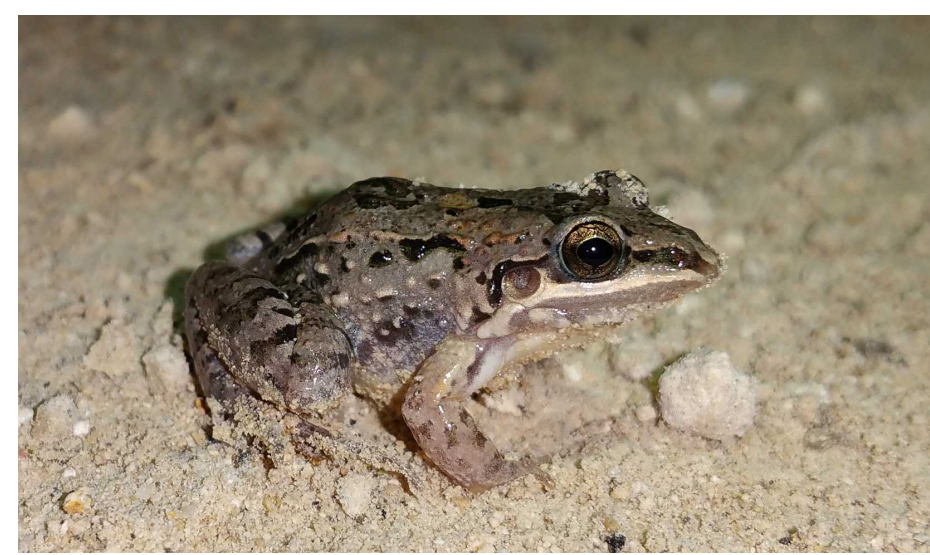

Figure 10. White-lipped foam frog (Leptodactylus fragilis). Credits: Michiko Squires, UF/IFAS

\section{White-Lipped Foam Frog}

Leptodactylus fragilis, $33-37 \mathrm{~mm}$ (1.3-1.5 in)

A small, terrestrial frog with a white stripe on its upper lip. Body primarily brown or gray with darker spots and blotches. Occupies a variety of habitats with permanent water. Makes foam nests.

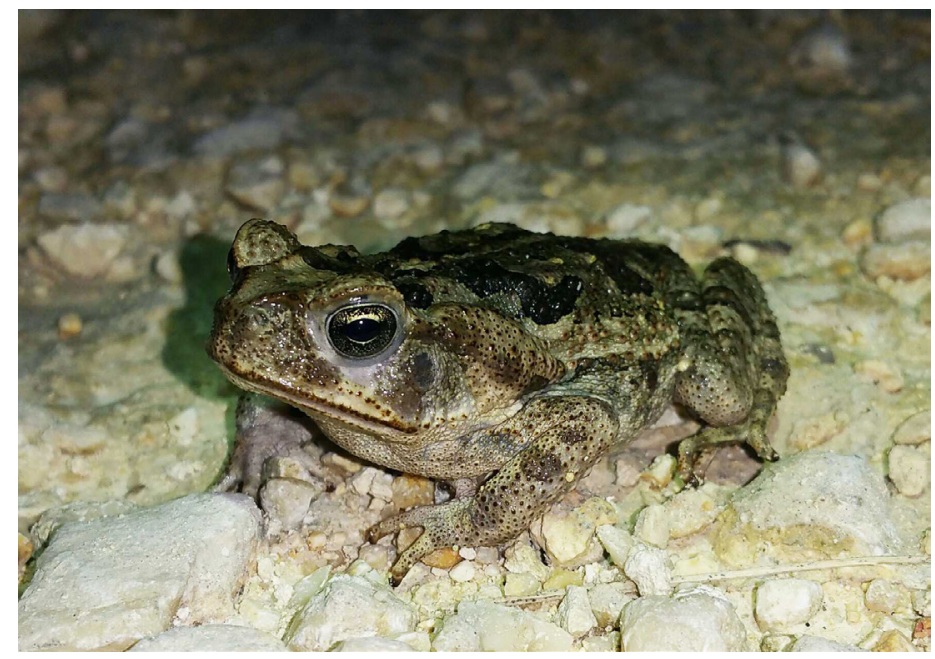

Figure 11. Cane toad (Rhinella marina).

Credits: Michiko Squires, UF/IFAS

\section{Cane Toad}

Rhinella marina, $80-210 \mathrm{~mm}$ (3.2-8.4 in)

Large, squat terrestrial toad with warty skin. Found in open habitats and very abundant in urban areas, often found under lights. Poison glands on its back secrete a white, milky toxin that is harmful to humans and can be fatal to dogs and other domestic animals.
For More Information

LAMANAI FIELD RESEARCH CENTER

Indian Church Village

Orange Walk, Belize

Tel: 011-501-678-9785

Email: info@lamanai.org

www.lamanai.org

crocdoc.ifas.ufl.edu

\section{Reference}

Lee, J. C. 2000. A Field Guide to Amphibians and Reptiles of the Maya World: The Lowlands of Mexico, Northern Guatemala, and Belize. Cornell University Press, Ithaca, New York. 